This final project is submitted by Melissa Allen

In Partial Fulfillment of the Requirements of

The PhD in Energy Science and Engineering

The University of Tennessee, Knoxville

\section{Preparing the Way} for New Policy

Regarding Adaptation of US Electricity Infrastructure to Climate Change 


\section{Table of Contents}

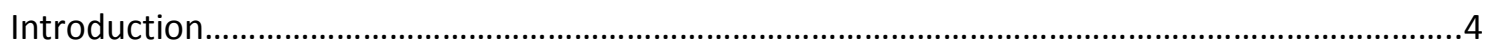

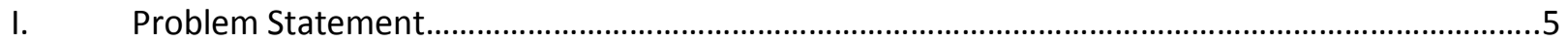

Vulnerability due to System Complexity.........................................................................

Vulnerability due to Heat Waves........................................................................................6

Vulnerability due to Hurricanes, Storm Activity and Flooding...........................................

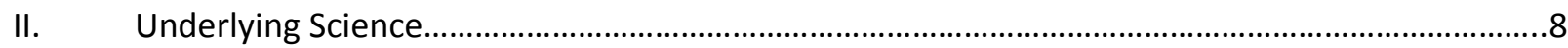

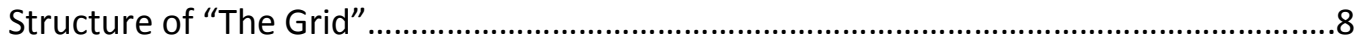

Vulnerability is Compounded by Climate Variability and Climate Change.........................9

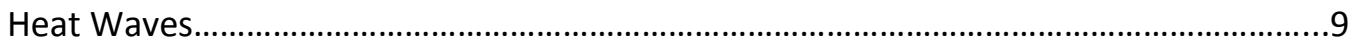

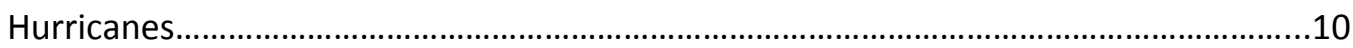

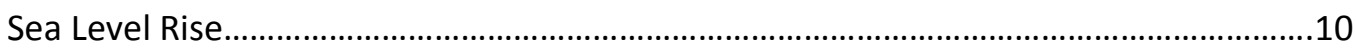

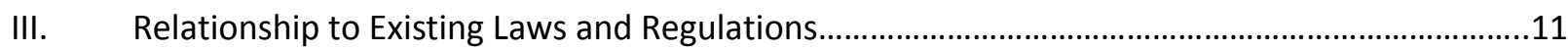

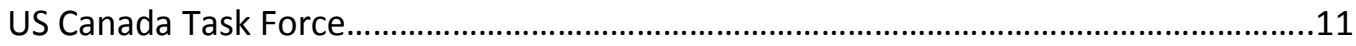

Reliability Impacts of Climate Change Initiatives Task Force..........................................12

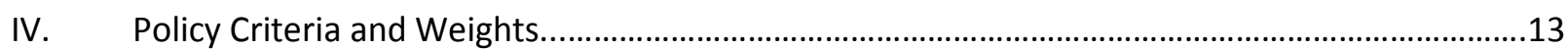

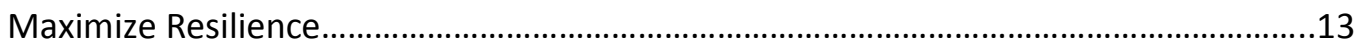

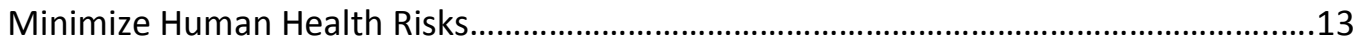

Minimize Further Environmental Risk.......................................................................13

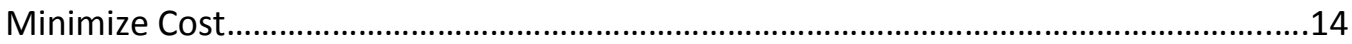

Maximize Political Feasibility......................................................................................14

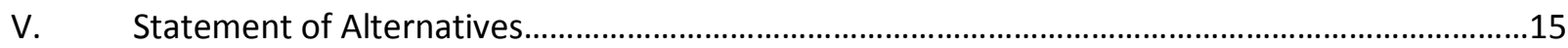

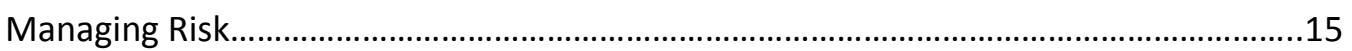

Developing Policy for Responsible Maintenance of Energy Systems..............................16

Minimizing Environmental Stresses to the System: Building Resilience.........................17

Maximizing Clean and/or Sustainable Energy Generation and Use...............................18

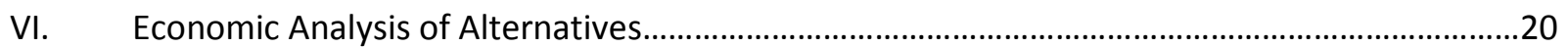

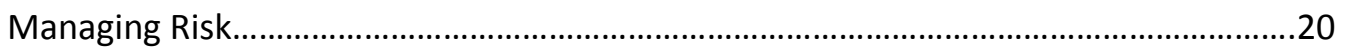

Developing Policy for Responsible Maintenance of Energy Systems.............................20

Minimizing Environmental Stresses to the System: Building Resilience.........................21

Maximizing Clean and/or Sustainable Energy Generation and Use...............................22

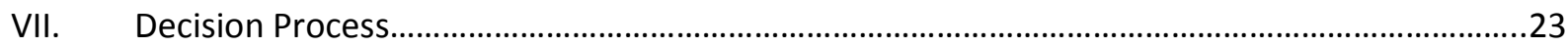

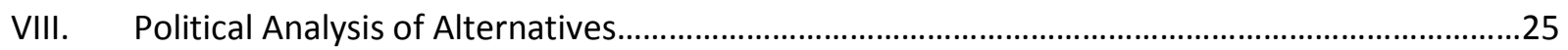

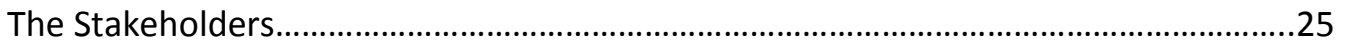

Managing Risk..........................................................................................................25

Developing Policy for Responsible Maintenance of Energy Systems.............................25

Minimizing Environmental Stresses to the System: Building Resilience........................26

Maximizing Clean and/or Sustainable Energy Generation and Use...............................26 


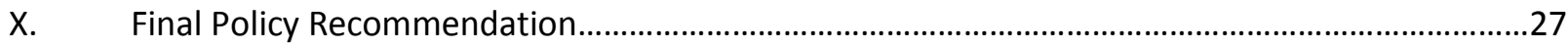

Developing Policy for Responsible Maintenance of Energy Systems............................27

Minimizing Environmental Stresses to the System: Building Resilience........................27

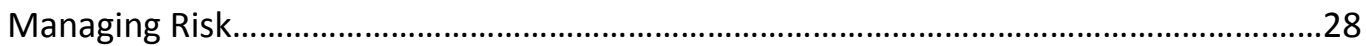

Maximizing Clean and/or Sustainable Energy Generation and Use................................28

Decision Matrix....................................................................................................29

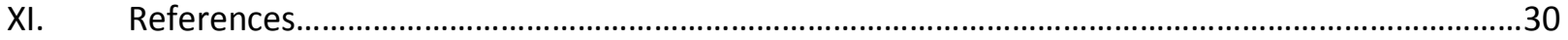




\section{Introduction}

The following pages represent the status of policy regarding adaptation of the electric grid to climate change and proposed directions for new policy development. While strides are being made to understand the current climate and to predict hazards it may present to human systems, both the science and the policy remain at present in an analytical state.

The policy proposed in this document involves first continued computational modeling of outcomes which will produce a portfolio of options to be considered in light of specific region-related risks. It is proposed that the modeling continue not only until reasonable policy at various levels of jurisdiction can be derived from its outcome but also on a continuing basis so that as improvements in the understanding of the state and trajectory of climate science along with advancements in technology arise, they can be incorporated into an appropriate and evolving policy. 


\section{Problem Statement}

A functioning power infrastructure is critical to the environment, economy and human life, yet several incidents in recent past suggest that current US infrastructure is vulnerable to extreme weather and climate events such as heat waves, hurricanes and flooding. Because of these vulnerabilities, the US is further underprepared to cope with predicted increases in frequency and intensity of these events due to climate change. These vulnerabilities are particularly prevalent in regions such as coastal areas that are more easily exposed to extreme weather, and they can lead to cascading consequences for the populations serviced by these and communicating sectors of the infrastructure.

Power generation failure is the most representative example of vulnerable infrastructure sectors since these systems are often the first affected by extreme weather phenomena, and since so much of the remaining infrastructure depends upon their proper functioning. Power failures can create a variety of threats to health including contamination of beaches, waterways and drinking water due to loss of electrically supported water pressure and/or flooding causing the release of sewage from water treatment plants. This sewage stream, then, can either flow into rivers, streams or lakes or back up into homes and businesses. [Lee, 2011]

Vulnerability due to System Complexity. An illustration of the complications that can occur as a result of power failure is seen in the example of the San Diego Outage of September, 2011. On September 8, 2011, at 3:38pm, San Diego County suffered a massive power outage, which affected a large area stretching from Orange County to Baja California and east into parts of Arizona. The two major power sources for the region became inoperable when a 500-kilovolt high-voltage transmission line from Arizona to California failed triggering a cascade of events that then knocked the San Onofre nuclear power plant offline.[Gustafson, 2011] The outage was initiated by lack of vigilance during a routine repair at a station in Yuma, Arizona, which caused one of three turbines generating electricity at a plant east of Mexicali to create an imbalance in the line running south from the San Onofre Nuclear Generating Station. The problem was compounded by an inability to monitor activities in neighboring balancing authorities, which prevented staff from limiting the blackout. [McDonald, 2011] The outage, thus, stopped power from coming into the county, halted the San Onofre nuclear power plant and shut down the entire system. The uncontained surge from the outage cut all power from a high-voltage transmission line connecting Arizona and California, and initiated a chain of events that also cut off the San Onofre plant. [Keegan, 2011]

The failure cascaded in two ways. First, the grid instantly lost about a third of its power supply. Second, the customers normally served by the Arizona power line were transferred to nearby power grids, including that of San Diego, all of which are interconnected. The addition of more customers to these grids immediately increased the amount of power being demanded from San Onofre and overwhelmed the power plant's capabilities.[Keegan, 2011]

Impacts to the affected communities were manifold. Electricity for millions of homes and businesses was unavailable for 12 hours. During the outage, non-operational generators in the area caused water pressure in the distribution system to reduce significantly, resulting in backflow and contamination to the clean supply to and from homes and businesses. San Diego residents were ordered to boil water prior to consumption. [Chillymanjaro, 2011] Once power was restored, two incidents of sewage spills occurred. One pump station caused approximately 2.6 million gallons of sewage to be spilled from three manholes onto Sorrento Valley Road and Sorrento Valley Boulevard into the storm drain system and 
ultimately into the Los Penasquitos Creek. The other spilled approximately 870,000 gallons of sewage into Sweetwater River and ultimately into San Diego Bay. [NRCC Executive Summary, 2011]

Vulnerability due to Heat Waves. An additional complication in the San Diego blackout was that the outage occurred on the last day of a heat wave during which temperatures had consistently reached 12 degrees (Fahrenheit) above average. [Gustafson, 2011] Combined with heating of the power lines due to the increased load of more customers using more power for indoor cooling, outdoor conditions also contributed to line fatigue and collapse. Similarly, in August 2003, when a high-voltage power line in northern Ohio made contact with overgrown trees and disconnected from the system as a result of line slackening due to excess heat from the high current flowing through the line along with elevated ambient temperatures, a power failure was instantiated. Although the incident should have activated an alarm in the control room of FirstEnergy Corporation, an Ohio-based utility company, it didn't, because the alarm system failed. As efforts were made to understand the events taking place, three other lines likewise sank into trees and switched off, forcing the remaining lines in service to operate at higher capacity. Because of the added load, these lines, too, shut down, generating a cascade of failures throughout southeastern Canada and eight northeastern states. [Minkel, 2008]

Millions of people in the Northeast lost electric power during the incident, but some of the most damaging effects were the result of water treatment plants and pumping stations shutting down. The blackout compromised the water supply in Detroit and Cleveland in at least two ways: first, by decreasing the pressure in water pumps, allowing bacteria to build up in municipal water systems; and second, by effectively shutting down sewage treatment facilities. As a result, millions of gallons of raw or partially treated sewage were discharged into the lake and streams from Ann Arbor, Michigan to communities east of Cleveland, Ohio. These discharges prompted officials in the Cleveland area to be on guard for signs of cryptosporidium, a parasite pathogen causing intestinal illness and even death in humans. [Johnson and Lefebvre, 2003] Air quality in the region was also compromised, as FirstEnergy's coal-fired power plant in Eastlake, Ohio, spewed a huge cloud of ash over a more than half-mile radius from the plant two hours before the blackouts began.[Johnson, 2003]

Vulnerability due to Hurricanes, Storm Activity and Flooding. A National Oceanic and Atmospheric Administration (NOAA) technical manual list of the deadliest and costliest hurricanes shows that large death totals were primarily a result of the 10 feet or greater rise of the ocean associated with most of the top thirty major hurricanes, and that a large portion of the damage in some of costliest tropical cyclones resulted from inland floods caused by torrential rain.[Blake et al., 2011] Hurricane Katrina of 2005 , for example, was responsible for at least $\$ 108$ billion of property damage and is by far the costliest hurricane ever to strike the United States. Irene (2005) sustained winds strong enough to damage power lines and cause widespread outages. It likewise brought enough rain to cause major flooding in a variety of regions. [Weiss, Boyd, Wheeler, CBS, 2011] Flooding in many areas during these storms was compounded by aging infrastructure. [Huffington Post, 2011; ASCE, 2009] Irene is blamed for 45 deaths in 13 states. [Boyd and Leger, 2011] Causes of death included personal blows due to storm-related traffic accidents and falling trees, drowning as a result of flooding and broken pipes, carbon monoxide poisoning produced by generators, and fires ignited by fallen power lines. [Associated Press, August 30, 2011] Additional impacts from Irene occurred in fifteen states, Connecticut, Delaware, Florida, Maine, Maryland, Massachusetts, New Hampshire, New Jersey, New York, North Carolina, Pennsylvania, Rhode Island, Vermont, Virginia and Washington, D.C. All of these states experienced power losses and flooding. Among the most severe additional consequences was a ruptured sewer main in the Baltimore Highlands area southwest of the city, which poured approximately 100 million 
gallons of raw sewage into the lower Patapsco River. Power outages also led to more than a dozen other sewage spills across the region. [Wheeler, 2011]

As climate conditions change, populations shift, and requirements for power increase; infrastructure must evolve to accommodate demand, and simultaneously to prevent risk to human welfare.

Symptoms of climate change are beginning to show: overall temperatures have risen in the past century resulting in longer heat waves and higher sea surface temperatures which have led to Arctic ice melt and sea level rise along with more frequent and more intense hurricanes. If warnings are heeded, policy and preparedness plans developed, and new building codes and zoning laws enacted with regard to power generation and dependent infrastructure, future deaths can be minimized and large property losses avoided. 


\section{Underlying Science}

America's energy infrastructure was given the grade of D+ recently in the American Society for Civil Engineers' 2009 Report Card for America's Infrastructure [ASCE, 2009]. Surprisingly, this grade indicates an improvement in power generation, distribution and maintenance over that of the previous grading period. While our energy infrastructure has now achieved a passing grade, however, it has not graduated from an overall grim assessment, granted fortified, fluid energy production and delivery proves a tough course to master. Complexity inherent in the power system complicates planning and preparedness for system failures. As previously illustrated, disruptions of the system, along with additional problems associated with cascading effects, were the impacts of the 2003 Northeastern blackout, the San Diego power outage, and the failures due to Hurricanes Irene and Katrina. This section focuses upon the causes of those failures; and upon the potential for much larger catastrophes due to climate change, should hardening measures not be taken.

\section{Structure of "The Grid"}

The North American power system is commonly referred to as "the grid," but the system actually comprises three distinct power grids. The Eastern Interconnection is located in and services the eastern two-thirds of the continental United States and Canada from Saskatchewan east to the Maritime Provinces, while the Western Interconnection covers the remaining western third of the continental United States (excluding Alaska), the Canadian provinces of Alberta and British Columbia, and a portion of Baja California Norte, Mexico. The third interconnection inhabits and services only Texas. The three interconnections are electrically independent of each other except for a few small direct current (DC) linkages [US Canada Task Force, 2004]. Within each separate interconnection, electricity flows over virtually all transmission lines from generators to loads; thus, a failure at a critical point in the network can quickly translate to failures within other sections of the same interconnection. These multiple failures can then cause cascading effects to additional infrastructure sectors such as water and wastewater treatment, transportation and public parks and recreation areas.

The US Canada Task Force, established to mitigate the effects of the 2003 Northeastern blackout, defines a cascading failure as "a dynamic phenomenon that cannot be stopped by human intervention once started. It occurs when there is a sequential tripping of numerous transmission lines and generators in a widening geographic area." [US Canada Task Force, 2004] Such cascades, a feature of each of the major outages previously described, are the development of a variety of factors: conductor contact with trees; overestimation of dynamic reactive output of system generators; inability of system operators or coordinators to visualize events on the entire system; failure to ensure that system operation was within safe limits; lack of coordination on system protection; ineffective communication; lack of "safety nets;" and inadequate training of operating personnel." [US Canada Task Force, 2004]

The 2009 Report Card focuses on two major weaknesses in the national electric grid: resilience and reliability. It states that utilities are generally prepared for local and regional responses, but that they lack the type of resilience needed should a much broader response be required. Regarding reliability, certain facilities are, for example, insufficiently girded against moderate wind loading. Pole failures in Florida due to Hurricane Wilma, whose winds were well below load design requirements, demonstrate this weakness. "If these structures had been designed from the $90 \mathrm{mph}$ winds required by NESE on transmission structures, distribution outages would have been reduced."[ASCE, 2009]. The complications and cascading consequences of the San Diego SDG\&E blackout described previously are also illustrative of the weaknesses in the power infrastructure. 


\section{Vulnerability is Compounded by Climate Variability and Climate Change}

As demonstrated in the previous section, many power failures are initiated by extreme weather events such as heat waves, hurricanes and flooding. According to studies cited in the Fourth Assessment Report of the Intergovernmental Panel on Climate Change Working Group I (IPCC AR4 WG I) [2007], the potential for such events to increase in intensity, duration and frequency with climate change is very high. While a wide range of extreme weather events is expected in most regions even with an unchanging climate, and observational data for model validation is limited to merely one and a half centuries, and several factors are usually in combination to produce one extreme event; it is nevertheless statistically reasonable to infer that substantial changes in the frequency of extreme events can result from a relatively small shift of the distribution of a weather or climate variable such as global temperature. Extremes are the infrequent events at the high and low end of the range of values of a particular variable, or, statistically speaking, at the tails of the frequency distribution. Figure 1 (below) illustrates this shift showing that as the mean of a normal distribution is shifted right, those events previously occupying only the highest percentiles now become a much higher probability.

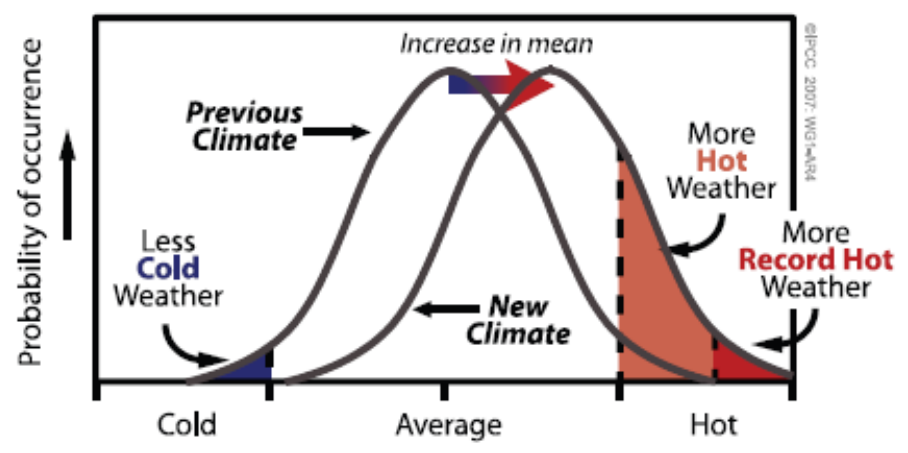

Figure 1. Climate Equilibrium Shift [IPCC WG I Technical Summary]

The following extreme events, which are related to elevated temperatures, are those most likely to affect power generation and to expose its vulnerabilities and their potential for additional cascading effects.

\section{Heat Waves}

As illustrated by the figure above, a very real consequence of global temperature rise for many regions is an increase in the annual number of heat waves (defined as the mean annual consecutive 3-day warmest nighttime minima event) [Meehl et al., 2004; Ganguly et al., 2009]. The record-breaking heat wave over western and central Europe in the summer of 2003 is an example of such an exceptional extreme. Additionally, records show that eleven of the last 12 years rank among the 12 warmest years on record since 1850. Rates of surface warming increased markedly in the mid-1970s and the global land surface has been warming at about double the rate of ocean surface warming since then [Brohan, 2006; Smith and Reynolds, 2005; Hansen et al., 2001; Lugina et al., 2005]. In a modeling study performed more recently, [Ganguly et al., 2009] it was found that observed heat wave intensities for the first decade of the $21^{\text {st }}$ century were even higher than the previously-modeled worst-case model projections of the same decade, implying an even steeper temperature growth curve for further projections for the current century [Ganguly et al., 2009]. 


\section{Hurricanes}

Just as land surface and adjacent lower atmospheric temperatures continue to increase with climate change, sea surface temperatures also continue to rise. These temperature increases, along with increased atmospheric water vapor levels that higher sea surface temperatures induce, foster the conditions leading to atmospheric convection and thunderstorms that generate hurricanes. Currently, hurricanes tend to form when sea surface temperatures exceed about 26 degrees Celsius. As sea surface temperatures increase, then, the area over which storms can form potentially expands.

The intensity of hurricanes, defined as the maximum wind speed achievable in a given thermodynamic environment [Emanuel, 2003], similarly depends critically on sea surface temperatures and atmospheric structure. According to the National Oceanic and Atmospheric Administration's [NOAA] Accumulated Cyclone Energy (ACE) index [Levinson and Waple, 2004], the collective intensity and duration of tropical storms and hurricanes during a given season is proportional to the maximum surface sustained winds squared. The power dissipation of a storm is proportional to the wind speed cubed. Thus, the effects of such storms are such that one large storm can have a much greater impact on the environment and the climate system than several smaller storms [IPCC AR4 WG I, 2007].

\section{Sea Level Rise}

Global sea level had risen by about $120 \mathrm{~m}$ during the several millennia that followed the end of the last ice age (approximately 21,000 years ago), and stabilized between 3,000 and 2,000 years ago. Various sea level indicators suggest that global sea level did not change significantly from then until the late 19th century. Modern observations of sea level change show evidence that sea level began again to rise during the 19th century. Estimates for the 20th century show that the global average sea level rose at a rate of about $1.7 \mathrm{~mm}$ yr-1 [IPCC AR4, WG I].

The rate of this sea level change over recent decades, however, has not been geographically uniform. Sea levels are forecast to rise more quickly over time from now on, especially in eastern North America and western Alaska [Zhang et al., 2000; Church et al., 2004; Meehl et al., 2007; Cooper et at., 2008; Wu, et al., 2009]. Many previous studies have documented the correlations between rising sea levels, coastal and inland erosion, and more frequent and intense storms in the US [Meehl et al., 2007; Travis, 2010]. Additionally, flooding resulting from sea level rise can present threats similar to those of the aftermath of hurricanes.

With regard to safeguarding power and other infrastructure, then, the key sources of climate vulnerability are increases in the frequency, intensity and duration of heat waves, hurricanes and tropical storms, and associated precipitation. For storms making landfall, the damage from winds and flooding, as well as storm surge, are especially of concern. Likewise, chronic flooding caused by sea level rise may manifest similar consequences. The likelihood of infrastructure remaining vulnerable to these threats depends upon resilience and reliability maintained by structural and operational codes. 


\section{Relationship to Existing Laws and Regulations}

In order to fortify US energy production, facilitate power distribution to all sectors of infrastructure, and protect the environment against power system failures, new regulations for policy and preparedness plans must be developed, and new building codes and zoning laws must be enacted. Executive Order 13211, established in May, 2001 by President George W. Bush provides a mechanism by which descriptions of such proposed laws may be submitted. Under this guidance, before an action that affects energy supply in any way can be taken, agencies requesting regulations must prepare a Statement of Energy Effects which describes the effects of the proposed action on energy supply, distribution, or use.

Upon review, the Administrator of the Office of Information and Regulatory Affairs, then, will provide guidance to the submitting agency on the implementation of the proposed regulation. The procedures taken by that Administrator refer to EO12866, issued by President William Clinton in 1993, which consider conflicts of economic or policy interest to affected agencies. Since the purpose of the proposed action in this case is to strengthen the system, reinforce it against environmental effects, and thereby increase its productivity and longevity; both long term risk and long term economic benefit will be stressed as weighed against the short term but potentially large capital investment.

EO13212, issued also by President George W. Bush on the same day as EO13211, emphasizes the importance of energy production and transmission "in a safe and environmentally sound manner". This order establishes an interagency Task Force to monitor and assist the agencies in their efforts to expedite actions to increase energy production and conservation, and to improve transmission of energy.

Since these Executive Orders, at least two such task forces have been deployed: the US Canada Task Force in response to the 2003 Northeast Blackout and the Reliability Impacts of Climate Change Initiatives Task Force of 2009.

\section{US Canada Task Force}

Much of the current policy regarding grid adaptation to extreme weather was established as a result of the 2003 Northeast Blackout by the US Canada Task Force, which investigated the sources of the crisis, determined its causes and provided recommendations. The Task Force judged that the Ohio phase of the blackout was caused by "deficiencies in specific practices, equipment, and human decisions by various organizations." A large contributor to the failure was insufficient reactive power, but the reasons for the insufficiency, the task force found, were deficiencies in corporate policies, lack of adherence to industry policies, and inadequate management of reactive power. [US Canada Task Force, 2004]

Recommendations of this task force fell into four categories: 1) government bodies in the U.S. and Canada should commit themselves to making adherence to high reliability standards paramount in the planning, design, and operation of North America's vast bulk power systems, and should conflicts arise between reliability and commercial objectives, they must be resolved in favor of high reliability; regulators and consumers should recognize that reliability is not free, and that maintaining it requires ongoing investments and operational expenditures by many parties; 3 ) recommendations have no value unless they are implemented-performance monitoring is needed along with accountability of senior management to comply with standards; and 4) the bulk power systems are among the most critical elements of our economic and social infrastructure--security-related actions are needed to enhance reliability. 


\section{National Energy Reliability Council: Reliability Impacts of Climate Change Initiatives Task Force}

US energy policy almost always starts with the National Energy Reliability Council (NERC). The main responsibility of this agency is the development of Reliability Standards for the energy industry. Once NERC adopts a given standard, it is passed to the Federal Energy Regulatory Commission (FERC) for approval and enforcement. In 2009, NERC appointed a Reliability Impacts of Climate Change on Infrastructure Task Force (RICCI) to investigate technological assessments of both long and short term impacts of climate change on electricity generation. The result of the task force was the production of two documents which addressed several climate scenarios and suggested action for each to maintain grid reliability. Mitigation and adaptation priorities were also part of these reports. Policy addressing these priorities is still under evaluation.

Mitigation priorities determined as a result of the task force include improvements in energy efficiency and conservation; incorporation of low emission energy technologies (renewables), clean coal (includes carbon capture and storage ), liquefied natural gas and biofuels (cellulose based, not corn); further development and implementation of advanced nuclear; and transition to electric vehicles and/or a hydrogen economy (long term). All of these changes in energy have associated impacts and risks to grid operation and reliability that need to be assessed; thus, firm policy regarding these changes is yet to be determined.

Adaptation priorities fall into two categories: Adapting to Climate Change, and Adapting to a Changed Resource Mix, that is, the addition of alternative energy sources to a smart grid. Examples of needed adaptive measures to climate change include "hardening" grid systems against extreme events, building or retrofitting for flood-proof critical facilities developing grid equipment for extreme environments, coping with changed load patterns and plant ratings strengthening emergency response and restoration plans, improving back-up telecom and grid control, and extending climate monitoring and recording. For adapting to changed resource mix, mechanisms for coping with intermittent resources, monitoring impacts of Smart Technologies (smart meters), and development of reliability and stability impacts of the extended grid are needed.

Continuing efforts in promoting grid reliability with regard to climate change from a variety of both government and nongovernment agencies are underway. These are discussed in the following sections. 


\section{Policy Criteria and Weights}

With the intensification of climate and weather extremes of the future due to climate change, effects to energy infrastructure have the potential to be severe. New policy regarding adaptation to these increased extremes must address several criteria, the most important being the maximization of resilience to the system. If the electricity sector can be made robust enough to withstand hurricane and storm activity, flooding, and heat waves, further environmental and human health risks as a result of electrical failure can be minimized. Best policy will be based upon political feasibility and cost effectiveness and will include representation by affected parties and appropriate governmental agencies in its development. Thus, in a sense, each of these criteria is dependent on the others in an essentially descending order.

\section{Maximize Resilience}

Weight: 0.3

Energy infrastructure must be built strong enough to demonstrate multi-hazard resilience. Built structures including operations facilities, computer systems and power lines must be capable of operating reliably in regions of specific vulnerabilities such as $90 \mathrm{mph}$ winds, storm surges, flooding and heat waves. Both routine and emergency communication capabilities and protocol at local scale and throughout the bulk power system must be established and practiced. Alternative sources of backup energy must be identified and available in case of emergency.

Because the means by which power is generated and distributed has not been resilient to extreme weather in the past, health and the greater environment have been exposed to the unnecessary secondary risks of weather extremes associated with prolonged and widespread power failure. Attention to system resilience is paramount to the attainment of the following two criteria: minimization of human health risk and of further environmental risk.

\section{Minimize Human Health Risks}

Weight: 0.2

Resilience in the energy infrastructure will minimize the risk to human health by ensuring that critical systems relying on electrical power can be restored immediately in the event of an emergency limiting the potential for wastewater overflow, excessive air pollution and/or drainage system surges.

It could be argued that minimization of human health risk should be the most important consideration with regard to new energy policy, but it has been demonstrated that the lack of resilience in the system has been a main cause of human health risk. If critical systems relying on electrical power can be restored immediately in the event of an emergency, the potential for wastewater overflow, along with that for excessive air pollution and/or drainage system surges is limited. A policy that at least requires updated emergency and communications procedures across both the bulk power system and affected sectors of the infrastructure as a whole should be considered, as the rehearsal and implementation of such procedures will serve to mitigate failures that have the potential to cascade throughout the entire infrastructure.

\section{Minimize Further Environmental Risk}

Weight: 0.2

The cleaner the energy practices in place, the lower the energy contribution to the overall causes of climate change. More immediately, however, environmental risks due to the effects of climate change must be minimized by keeping the electrical power supply as continuous as possible. Policy solutions should facilitate this objective. Alternatives that best meet this criterion will include ecologicallyfriendly maintenance plans for the built structures involved in power generation and distribution along 
with emergency and communications procedures necessary for managing system failure quickly and/or responding to indicators of imminent failure.

\section{Minimize Cost}

Weight: 0.15

Costs involved in redeveloping systems to accommodate large stresses to them can become prohibitive, especially if such redevelopment amounts essentially to "starting over". While a redesign of the electricity infrastructure may be desirable, a more achievable solution will involve minimizing cost: making changes that build upon current technology while advancing the state of the system as efficiently as possible. The first step in cost minimization is, naturally, research such as modeling of systems and development of a portfolio of options. Cost/benefit analyses that result in the least expenditure for the most protection will be the first considered and the most likely to gain support. Modeling efforts, while themselves an expense, serve to minimize waste before projects begin. This criterion receives less weight than the previous three, however, because if the prior criteria are not met, there is no point in implementing anything.

\section{Maximize Political Feasibility}

Weight: 0.15

If costs can be kept reasonable, solutions have a better chance of being heard and considered by a diverse spectrum of policy makers. Likewise, if the solutions to girding the system against the threats of climate change can also serve other long term goals such as developing resistance to terrorist attacks or saving money by building in energy efficiency or reducing the number or the extent of damage due to natural disasters, a larger variety of stakeholders will support those solutions. Thus, while the primary goal remains to maximize resilience, policy that shows a wide range of benefits for such measures have the potential to gain political traction.

America's energy infrastructure is in need of vast improvement as we move forward into the environmental challenges of the twenty-first century. As we develop our best strategy for raising the longevity, performance, and environmental friendliness of that infrastructure, we must weigh costs and gains economically, environmentally and politically. Each of the criteria above must be evaluated from these perspectives. Both long-term and short-term portfolios of alternatives must be developed; and planning and policy must proceed according to optimum solutions for each region's goals and requirements within the greater system. 


\section{Statement of Alternatives}

The State Energy Assurance Guidelines published by the National Association of State Energy Officials, cites four specific groups of threats to the security of the energy infrastructure, three of which suggest enhanced vulnerability to climate change:

- Natural attacks caused by nature (e.g., hurricanes, tornadoes, floods, wildfires, earthquakes);

- Accidental attacks caused by technological failure (e.g., pipeline rupture, levee breaches, chemical spills, nuclear or biological contamination);

- Systemic threats caused by the physical inability of energy delivery systems to meet demand.

Recent history has demonstrated these vulnerabilities within the current climate regime. As potential for higher frequency and intensity of hurricanes, flooding and storm activity along with longer durations of heat waves, is realized through climate change; adaptive policy, and perhaps increased government oversight must be developed to protect the reliability of power generation and distribution. The systems are highly complex and government is uniquely positioned to facilitate the gathering and integration of information regarding the large-scale dynamics of the systems and the threats they face, and to work with industry to identify solutions that increase reliability and security. (Villasenor, 2011)

Balance between the efficiency of complex systems and their robustness to accident or attack must also be evaluated. While efficiency is important, increased robustness even at the cost of efficiency is increasingly necessary for the prevention of unforeseen consequences. With the implementation of the smart grid checks and balances must be put into place.

Currently, there is insufficient understanding of energy-associated infrastructure interdependencies that can go beyond local jurisdiction and State boundaries. There is also insufficient recognition of the need for a regional integrated energy reliability strategy that takes into account supply, distribution, energy efficiency, security, climate change, and in particular, disaster resilience needs.(DHS, DOE, 2010) In order to promote awareness of these issues and to develop policy that addresses them. A variety of modeling efforts are underway. For this study it is proposed that the modeling continue not only until reasonable policy can be derived from its outcome but also on a continuing basis so that as improvements in the understanding of the state and trajectory of climate science along with advancements in technology arise, they can be incorporated into an appropriate and evolving policy.

\section{Managing Risk}

In order to manage the risks to energy infrastructure associated with climate change, there must be a process in place that allows for flexible and dynamically evolving adaptation of the system to continued updates and improvements in the scientific understanding of the impacts of climate change on various regions.

The National Infrastructure Protection Plan (NIPP) has developed a Risk Management Framework for Energy Infrastructure. This framework is assesses risk based on consequences, vulnerability and threats to asset systems and networks and compares results with actual outcomes as the framework proceeds. The system develops and implements protective programs and resiliency strategies along with measurement tools to assess the effectiveness of proposed strategies. The system has the capability to develop portfolios for investment and changes to the energy infrastructure along with built-in effective 
short-term responses to reduce consequences and allow for more rapid recovery and continuous evaluation of effectiveness.

NIPP Risk Management Framework

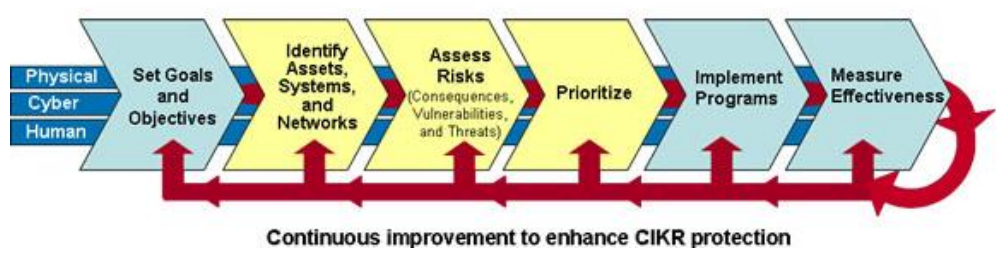

\section{Developing Policy for Responsible Maintenance of Energy Systems}

As the framework for risk management allows for continuous development of advance risk prevention, so must policy for the maintenance of energy systems evolve to suit the findings and promote safety.

After the 2003 Northeast blackout, NERC and its ten Regional Reliability Councils sought to update its system operating and planning standards toward a higher emergency threshold and thus, a more reliable transmission grid; and to gain the backing of the Federal Energy Regulatory Commission (FERC) for their efforts. In response to this request and to the results of the US Canada Task Force recommendations, FERC established clear, unambiguous, measurable and enforceable Reliability Standards for the Energy Policy Act (EPAct) issued in 2005. As needed since the act, NERC has proposed a variety of amendments and interpretations to the act. (FERC)

In the meantime, utility industry restructuring has divided ownership and operation of generation, transmission and distribution activities of electric service among different entities. These groups are primarily the Independent System Operators (ISOs) and Regional Transmission Organizations (RTOs). ISOs and RTOs in the United States have been authorized by FERC to implement aspects of the Energy Policy Act of 1992 and subsequent FERC policy directives. (US Canada Task Force)

In 2009, new policy, led by the North American Electric Reliability Corporation (NERC) developed the Reliability Impacts of Climate Change Initiatives Task Force (RICCITF) to develop technological assessments of both long and short term impacts of climate change on electricity generation. At present, two documents have been produced which address several climate scenarios and suggested action for each to maintain grid reliability (NERC_2009_LTRA.pdf, RICCI_2010.pdf). The task force was disbanded November 4, 2010 having fulfilled the requirements of its scope for the RICCITF. Because of the uncertainties associated with climate predictions and the continual improvement of the metrics by which it is predicted and evaluated, periodic updates of this type should be part of NERC's ongoing development of reliability standards. Reliability standards include resource and demand balancing; communications; critical infrastructure protection; emergency preparedness and operations; facilities design; connection and maintenance; interchange scheduling and coordination; interconnections reliability operations and coordination; modeling, data and analysis; nuclear; personnel performance training and qualifications; protection and control; transmission operations; transmission planning; and voltage and reactive. All of these aspects of grid management are affected by extreme weather and climate change. 


\section{Minimizing Environmental Stresses to the System: Building Resilience}

Energy infrastructure must be built strong enough to demonstrate multi-hazard resilience, both locally and for broader base. It must also be capable of operating reliably in regions of specific vulnerabilities such as $90 \mathrm{mph}$ winds, storm surges, flooding and heat waves.

The State Energy Assurance Guidelines identify four infrastructural qualities of resilience: 1) Robustness, the inherent strength or resistance in a system to withstand external demands without degradation or loss of functionality; 2) Redundancy, system properties that allow for alternate options, choices, and substitutions under stress; 3 ) Resourcefulness, the capacity to mobilize needed resources and services in emergencies; and 4) Rapidity, the speed with which disruption can be overcome and safety, services, and financial stability restored. T.D. O'Rourke (2007) expands upon these qualities in his article "Critical Infrastructure, Interdependencies, and Resilience," published in The Bridge. He outlines technical, organizational, social and economic responsibilities for maintaining system resilience as shown in the table below.

TABLE 1 Matrix of Resilience Qualities with Examples Pertaining to the Technical, Organizational, Social, and Economic Dimensions of Infrastructure

\begin{tabular}{|c|c|c|c|c|}
\hline Dimension/Quality & Technical & Organizational & Social & Economic \\
\hline Robustness & $\begin{array}{l}\text { Building codes and } \\
\text { construction } \\
\text { procedures for new } \\
\text { and retrofitted } \\
\text { structures }\end{array}$ & $\begin{array}{l}\text { Emergency } \\
\text { operations planning }\end{array}$ & $\begin{array}{l}\text { Social vulnerability } \\
\text { and degree of } \\
\text { community } \\
\text { preparedness }\end{array}$ & $\begin{array}{l}\text { Extent of regional } \\
\text { economic } \\
\text { diversification }\end{array}$ \\
\hline Redundancy & $\begin{array}{l}\text { Capacity for } \\
\text { technical } \\
\text { substitutions and } \\
\text { "work-arounds" }\end{array}$ & $\begin{array}{l}\text { Alternate sites for } \\
\text { managing disaster } \\
\text { operations }\end{array}$ & $\begin{array}{l}\text { Availability of } \\
\text { housing options for } \\
\text { disaster victims }\end{array}$ & $\begin{array}{l}\text { Ability to substitute } \\
\text { and conserve } \\
\text { needed inputs }\end{array}$ \\
\hline Resourcefulness & $\begin{array}{l}\text { Availability of } \\
\text { equipment and } \\
\text { materials for } \\
\text { restora-tion and } \\
\text { repair }\end{array}$ & $\begin{array}{l}\text { Capacity to } \\
\text { improvise, innovate, } \\
\text { and expand } \\
\text { operations }\end{array}$ & $\begin{array}{l}\text { Capacity to address } \\
\text { human needs }\end{array}$ & $\begin{array}{l}\text { Business and } \\
\text { industry capacity to } \\
\text { improvise }\end{array}$ \\
\hline Rapidity & $\begin{array}{l}\text { System downtime, } \\
\text { restoration time }\end{array}$ & $\begin{array}{l}\text { Time between } \\
\text { impact and early } \\
\text { recovery }\end{array}$ & $\begin{array}{l}\text { Time to restore } \\
\text { lifeline services }\end{array}$ & $\begin{array}{l}\text { Time to regain } \\
\text { capacity, lost } \\
\text { revenue }\end{array}$ \\
\hline
\end{tabular}

Since 2003, three of these resilience qualities are regularly analyzed and updated by the NERC Reliability Standards committee: Redundancy, Resourcefulness and Rapidity, since failure in these areas will be apparent in the day to day functioning of the power generation network. Robustness of the built structures of the electricity infrastructure in light of increasing weather extremes due to climate change, however, has yet to be fully explored.

In 2011 the National Institute of Standards and Technology (NIST) began to develop the capability for predicting the effects of hazards on the performance of complex built structures. The effects of these natural threats to be investigated are extreme wind, storm surge, fire, flooding, impacts, load bearing, and multi-hazard. Tests for structural response are included in the investigation as well as loss 
estimates for disaster consequences. The outcome of the project will be the development of costeffective designs of new buildings for power generation and rehabilitation of old buildings for the purpose. Recent disasters and failures involving structures will inform the studies. The program will produce results that will inform new building codes and plans for bringing both old and new structures up to those standards.

\section{Maximizing Clean and Sustainable Energy Generation}

Although our past energy habits have already caused the climate equilibrium shift in which we currently find ourselves, maximization of clean and sustainable energy generation can begin a mitigation process for climate change in the long run. Multiple drivers for actions can reduce emissions and can produce multiple benefits. The most promising policy approaches are those that capitalize on natural synergies between climate protection and development priorities to advance both objectives simultaneously. Many of these synergies are in energy demand (e.g., efficiency and conservation, education and awareness) and some in energy supply (e.g., renewable options).

Incorporating energy sources such as solar, wind and nuclear into a Smart Grid that can store and distribute that energy strategically according to need will lead to less emission of greenhouse gasses reducing the amount of global radiative forcing and resultant climate changes. The use of alternatives to conventional electricity, petroleum, and natural gas has the potential to enhance energy security by helping to distribute generation and diversify supply among various locations. Not only will the use of alternative energy sources help reduce a given power generation station's emission of greenhouse gases supporting the mitigation of climate change, these alternative sources can provide needed backup in the case of an energy emergency. The State Energy Assurance Guidelines (SEAG) indicate that in order to make best use of alternative energy sources, statewide inventories of energy alternatives should be developed. This work, begun in 1990, falls under the responsibilities of the US Energy Information Administration (EIA). The work was sustained until 2010, at which time funding was cut. Among the cuts in services made to accommodate the budget cut were to terminate annual data collection and report on geothermal space heating (heat pump) systems, to terminate annual data collection and report on solar thermal systems and to reduce data collection from smaller entities across a range of EIA electricity and coal surveys. In the past, this record has allowed for the calculation of the potential contribution to state energy supply from a variety of energy sources including alternative ones, and for more accurate assessment of energy assurance risk. It continues similarly in its reduced capacity, but all resources will not continue to be reported.

As these records were established, they have been accessible to power companies, so that cooperative relationships among the power companies and alternative energy supply companies could be built and maintained. This valuable work should be continued in full to assure that renewable energy sources can become grid connected and used as much as practicable as technology improves. In an emergency, in particular, this cooperation can allow primary energy producers immediate knowledge of and access to available solar, wind or bioenergy sources and acceleration of energy efficiency measures to provide enhanced safety for citizen and time for repair and restoration to failed systems. Continued availability of these records is necessary.

Additionally, backup capabilities such as NextEnergy's Renewable Energy Mobile Utility System, a 7-ton rechargeable battery pack used to supply computer-grade electricity for military field applications, could, upon its fulfillment of military obligations, be commissioned for other non-military applications. This battery can be recharged using fossil fuel, solar or wind energy. In the event that a specific grid- 
based emergency prevents rerouting of sources within the system, such units could be be deployed to keep the most important operations functioning.

Through flexible policy initiatives and continuous monitoring, assessment and adaptation of their efficacy, the US capable of rebuilding and reforming its infrastructure in a dynamically-evolving manner such that efficiency and robustness are balanced and both human and natural systems are strengthened against the changing climate. 


\section{Economic Analysis of Alternatives}

\section{Managing Risk}

The National Infrastructure Protection Plan's (NIPP) Risk Management Framework for Energy Infrastructure establishes the processes for combining consequence, vulnerability, and threat information to produce a "comprehensive, systematic and evolving assessment of risks to assets, systems, networks, and functions of potential interest."

This protocol lends itself as readily to risk assessment associated with climate change as it does to some of its other current functions: situational awareness to incident commanders, crowd evacuation at high impact events, DNA modeling for relationship identification and multimodal biometric identification, etc. It is currently one of thirty-two services among the suite of Science \& Technology Research, Development, Acquisitions, and Operations within the Department of Homeland Security budget.

Actual budgetary obligation for all of these operations in 2011 was $\$ 55,622,000.00$. Assuming all operations are given equal shares of this budget, the Risk Management Framework budget for 2011 amounted to $\$ 1,738,188$. Continuation of the Framework at the current rate would support the continued integration of climate change risk assessment into the system.

Annual Cost Risk Management (base 2011): $\$ 1,738,188$

\section{Developing Policy for Responsible Maintenance of Energy Systems}

As the framework for risk management allows for continuous development of advance risk prevention, so must policy for the maintenance of energy systems evolve to suit the findings and promote safety.

In 2009, new policy, led by the North American Electric Reliability Corporation (NERC) developed the Reliability Impacts of Climate Change Initiatives Task Force (RICCITF) to develop technological assessments of both long and short term impacts of climate change on electricity generation. This effort was included in the 2009 budget for reliability standards and was the result of a collaboration of primarily NERC staff and several outside consultants. Combined salary of all NERC reliability standards staff for 2009 was $\$ 2,476,574$. The portion of this amount allocated to RICCI is not explicitly reported. Because of the uncertainties associated with climate predictions and the continual improvement of the metrics by which it is predicted and evaluated, periodic updates of this type should be part of NERC's ongoing development of reliability standards. 


\section{Minimizing Environmental Stresses to the System: Building Resilience}

Energy infrastructure must be built strong enough to demonstrate multi-hazard resilience, both locally and for broader base. It must also be capable of operating reliably in regions of specific vulnerabilities such as $90 \mathrm{mph}$ winds, storm surges, flooding and heat waves. Costs associated with modeling efforts aimed at resilience policy are shown in the expanded table below.

TABLE 2 Matrix of Resilience Qualities with Examples Pertaining to the Technical Dimensions of Infrastructure (Expansion on O'Rourke, 2007)

\begin{tabular}{|c|c|c|c|}
\hline Dimension/Quality & Technical & Requirements & Total Cost \\
\hline Robustness & $\begin{array}{l}\text { Develop building } \\
\text { codes and } \\
\text { construction } \\
\text { procedures for } \\
\text { new and } \\
\text { retrofitted } \\
\text { structures }\end{array}$ & $\begin{array}{l}\text { Develop capability for predicting the effects of } \\
\text { hazards on the performance of complex built } \\
\text { structures. Effects of these natural threats to be } \\
\text { investigated: Extreme wind, storm surge, fire, } \\
\text { flooding, impacts, load bearing, multi-hazard. } \\
\text { Tests for structural response. Provide loss } \\
\text { estimates for disaster consequences. Develop } \\
\text { cost-effective design of new buildings and } \\
\text { rehabilitation of old buildings. Learn from recent } \\
\text { disasters and failures involving structures. } \\
\text { National Institute of Standards and Technology } \\
\text { (NIST) }\end{array}$ & $\begin{array}{l}\$ 5,000,000.00 \\
\text { Recommendations } \\
\text { to be delivered in } \\
\text { advance of the } \\
\text { release of the } \\
2016 \text { American } \\
\text { Society of Civil } \\
\text { Engineers/Structu } \\
\text { ral Engineering } \\
\text { Institute } \\
\text { (ASCE/SEI) } \\
\text { standards }\end{array}$ \\
\hline Redundancy & $\begin{array}{l}\text { Capacity for } \\
\text { technical } \\
\text { substitutions and } \\
\text { "work-arounds" }\end{array}$ & $\begin{array}{l}\text { Backup Generators and bulk power system } \\
\text { visibility and communication }\end{array}$ & $\begin{array}{l}\text { Included in NERC } \\
\text { Reliability } \\
\text { Standards }\end{array}$ \\
\hline Resourcefulness & $\begin{array}{l}\text { Availability of } \\
\text { equipment and } \\
\text { materials for } \\
\text { restoration and } \\
\text { repair }\end{array}$ & $\begin{array}{l}\text { Performance training, protection and control } \\
\text { (NERC) }\end{array}$ & $\begin{array}{l}\text { Included in NERC } \\
\text { Reliability } \\
\text { Standards }\end{array}$ \\
\hline Rapidity & $\begin{array}{l}\text { System downtime, } \\
\text { restoration time }\end{array}$ & $\begin{array}{l}\text { Dependent on backup generation and response } \\
\text { training of personnel (NERC) }\end{array}$ & $\begin{array}{l}\text { Included in NERC } \\
\text { Reliability } \\
\text { Standards }\end{array}$ \\
\hline
\end{tabular}

Total Cost (base 2011): $\$ 5,000,000$ 


\section{Maximizing Clean and/or Sustainable Energy Generation and Use}

In order to make best use of alternative energy several actions should be taken (SEAG, 2009):

\begin{tabular}{|c|c|c|}
\hline Strategy & Procedure & Cost \\
\hline $\begin{array}{l}\text { 1. Develop Statewide } \\
\text { Inventories of Energy } \\
\text { Alternatives }\end{array}$ & $\begin{array}{l}\text { This falls under the responsibilities of the US Energy } \\
\text { Information Administration (EIA). } \\
\text { Among the cuts in services made to } \\
\text { accommodate the budget cut were to } \\
\text { - Terminate annual data collection and } \\
\text { report on geothermal space heating (heat } \\
\text { pump) systems. } \\
\text { - Terminate annual data collection and } \\
\text { report on solar thermal systems. } \\
\text { Reduce data collection from smaller } \\
\text { entities across a range of EIA electricity } \\
\text { and coal surveys. }\end{array}$ & $\begin{array}{l}\text { The } 2011 \\
\text { budget for this } \\
\text { agency has been } \\
\text { reduced to } \\
\$ 95.4 \text { million, } \\
\text { which reflects a } \\
\text { reduction of } \\
\$ 15.2 \text { million, or } \\
14 \text { percent from } \\
\text { the } 2010 \\
\text { budget. Future } \\
\text { budgets should } \\
\text { reinstate this } \\
\text { valuable service. }\end{array}$ \\
\hline $\begin{array}{l}\text { 2. Make the Records } \\
\text { Accessible to Power } \\
\text { Companies }\end{array}$ & $\begin{array}{l}\text { Records through } 2010 \text { are available publicly at } \\
\text { http://www.eia.gov/cneaf/electricity/page/data.html. } \\
\text { These records are vital to the communication and } \\
\text { emergency response among power companies, } \\
\text { alternative energy supply companies and the } \\
\text { communities they serve. }\end{array}$ & $\begin{array}{l}\text { Falls under the } \\
\text { same EIA } \\
\text { budget as above }\end{array}$ \\
\hline $\begin{array}{l}\text { 3. Build and Maintain } \\
\text { Cooperative Relationships } \\
\text { among Power Companies } \\
\text { and Alternative Energy } \\
\text { Supply Companies (Grid } \\
\text { Connections) }\end{array}$ & NERC & $\begin{array}{l}\text { Included in } \\
\text { NERC Reliability } \\
\text { Standards }\end{array}$ \\
\hline $\begin{array}{l}\text { 4. Employ Battery Backup } \\
\text { Rechargeable by a Variety of } \\
\text { Types of Energy Sources }\end{array}$ & NextEnergy REMUS & $\begin{array}{l}\text { Pricing not } \\
\text { available except } \\
\text { by written } \\
\text { request. }\end{array}$ \\
\hline
\end{tabular}

Annual Cost (base 2011): $\$ 111,000,000.00$ 


\section{Decision Process}

Policy development for the purpose of risk aversion is a tricky business, especially if the identified risks most affect groups or individuals living in other geographic locations or at some future time from those developing the policy. Until a society sees personal tangible or immediate evidence of a stated problem, such as immediate health or economic compromise, its members hesitate to give up the current level of life that they enjoy in favor of solving a problem they may perceive does not exist. Yet if the validity of the problem can be demonstrated, and that solutions to the problem incur minimal cost with maximum benefit, society can be convinced to act on behalf of the common good.

Since the 1970s it has been widely believed that two of the largest environmental problems are climate change and depletion of the ozone layer. In 1989, the Montreal Protocol on Substances that Deplete the Ozone Layer was passed and met with widespread acceptance and implementation. US President Ronald Reagan was pleased to ratify the Protocol and called it an "important milestone for the future quality of the global environment." [Sunstein, 2006] In later years, Ghanaian diplomat Kofi Annan hailed it as "perhaps the single most successful international agreement to date."[The Ozone Hole]

The 1997 Kyoto Protocol, on the other hand, which commits industrialized nations to reducing greenhouse gas emissions (excesses of which are the cause of climate change), has received much less support, and was rejected altogether by US President George W. Bush and a 95-0 US Senate vote as "an unfair and ineffective means of addressing global climate change concerns." Additionally, developed countries who have ratified the treaty are not consistently abiding by it, and developing nations such as India and China have refused to join the Kyoto Protocol, although it is in those nations that greenhouse gases are increasing most rapidly.[Sunstein, 2006]

The Montreal and the Kyoto Protocols are based on similar issues: human emissions to the atmosphere that cause long-lasting harm to the environment as revealed by scientific work, the necessity for cooperation among nations for mitigation, and the social inequity of ramifications should the problem go unaddressed. Yet the passage of the Montreal Protocol was seen as a viable solution to a real problem, while the Kyoto Protocol was seen as oppressive, unnecessary and prohibitively expensive to American corporations.

The main differences between the two protocols are in the presentation of their cost-benefit analyses and in their methods of implementation. In the case of the Montreal Protocol, it was perceived by the US that the benefits far outweighed the costs of the implementation. In fact, it appeared to the United States that it had so much to lose from depletion of the ozone layer that it would have been worthwhile for the nation to act unilaterally to take the steps required by the Montreal Protocol. On the other hand, it was perceived that if the United States complied with the Kyoto Protocol, it would both spend a great deal and gain relatively little.[Sunstein, 2006] Additionally, rewards were built into the execution of the steps of the Montreal Protocol such that each step in reducing ozone depletion created incentives for countries to take yet another step.[autogeno.us]

Whether a society in a perfect world should base policy decisions purely on moral obligation and not on personal cost is hard to say, but it is certainly reasonable for real world policymakers to consider both in making decisions that obligate their citizens to practices that for whatever reason stand to limit their economic productivity and potentially threaten their means of livelihood altogether. 
The first step toward the development of a climate adaptation policy for the electricity infrastructure in which the benefits outweigh the costs is through scientific analysis of the options available. This approach is a blend of an Analysis-Centered and an Elite Corps decision-making mode. The goal of this analysis is that of a satisficing strategy in which the costs of decision-making are considered in the outcome calculus and the solutions satisfy a set of agreed-upon constraints. Such an analysis should include not only weather and climate projections for the future, but also energy demand as a result of climate change. The analysis should draw on examples of historical extreme weather and its previous consequences to the electricity infrastructure and should extrapolate to additional potential scenarios in which the electrical system becomes further stressed as a result of climate change.

For example, electricity is required for cooling while heating can be accomplished with natural gas. With a significant rise in global temperature, an even greater load will be placed on the electrical grid during the summer months than it has been historically. In dry climates, significant temperature increases result in drought. Should a drought be severe or prolonged, migration from such areas may ultimately be necessary. Increased population in the areas receiving the migrants will then increase the load on the electrical system in those areas. If those areas are located in on the coasts of the US, which are more vulnerable to hurricanes (activity of which is predicted to intensify with climate change), their vulnerability is further increased with these new complexities. Integrated Assessment Models can assist in the analysis of vulnerability by region, and of the potential costs of implementing adaptive measures as contrasted with the costs of inaction.

Experts in the interdisciplinary fields of both environmental science and energy engineering should be involved in the process, along with representatives of the agencies that the policy would affect; and collaboration regarding solutions should produce portfolios outlining the various scenarios along with calculated costs of a variety of solutions for each. The solutions should take into account the results of efforts already underway by such agencies as the National Infrastructure Protection Plan (NIPP), the Department of Energy (DOE), the North American Electric Reliability Corporation (NERC), the National Institute of Standards and Technology (NIST) and the US Energy and Information Administration.

A final portfolio of solutions should be submitted to policy makers at a variety of levels, local, state, regional and federal. The best solutions to implement will differ according to region, as each region will have its own particular manifestations of climate change and thus its own vulnerabilities. Perhaps an overarching decision metric can be established at the federal level with the flexibility for successively more local agencies to act within the best interests of their respective constituent populations and environments. Built into this process also should be the potential for policy to evolve as both the science and the changes in climate evolve. And as with the implementation of the Montreal Protocol, a system for positive feedback should be part of the evolutionary process, with each step in adaptation to and mitigation of climate change creating incentives for communities to take yet another step in this direction. 


\section{Political Feasibility of Alternatives}

For most new policy that is made at varying levels of government, interested stakeholders must be aware of political windows of opportunity to present their proposals in light of the interests of policy makers and their constituents. It is difficult to pass new policy unless clear necessity for the policy is demonstrated to the satisfaction of the policy makers. If risk of harm to the constituents or to the government of those constituents can be shown, however, policymakers are willing to consider potential plans for aversion of those risks. Although the risks of climate change to a variety of aspects of human life have been shown with both measured and modeled scientific data, much of the public is still disinclined to take mitigative action especially if it means altering economically rewarding lifestyles to do so, since quite probably the necessary changes are already too late to avert the coming consequences. Many stakeholders in the energy infrastructure do stand to lose as the climate changes if they are unwilling to take at least preventative adaptive measures.

\section{The Stakeholders}

There are many stakeholders in policy related to energy infrastructure adaptation to climate change. The power companies and energy distributors, who stand to lose money in the short term if costly adjustments must be made to power generation, diversification, storage and delivery. They may win, however if cost-efficient changes can be made that fortify the system against attacks of extreme weather (and, as a byproduct, a variety of terrorist measures or other disruptions) so that power remains continuous under these conditions. Energy consumers benefit from uninterrupted and power as well, but may be averse to the costs passed on to them by the power companies for upgrades. If part of adaptation to climate change includes reduction in consumption of fossil fuels, those who head and who are employed by these industries could lose money and jobs. Those who produce alternative energy would benefit, however, for the same reason, if more production is sent their way in an effort to mitigate climate change.

\section{Managing Risk}

The National Infrastructure Protection Plan (NIPP) Risk Management Framework for Energy Infrastructure establishes processes for combining consequence, vulnerability, and threat information to produce a "comprehensive, systematic and evolving assessment of risks to assets, systems, networks, and functions of potential interest." This computational modeling effort, geared to assess risk, ultimately develops and implements protective programs and resiliency, and then evaluates their effectiveness. This protocol is currently one of thirty-two services among the suite of Science \& Technology Research, Development, Acquisitions, and Operations within the Department of Homeland Security budget. Continuation of the Framework at the current rate would support the continued integration of climate change risk assessment into the system, and thus requires no new policy-only continued support. Since infrastructure protection is important from a variety of perspectives, and assessment of various risks to the infrastructure dictates the level of protection needed, political feasibility for this alternative is fairly high.

\section{Developing Policy for Responsible Maintenance of Energy Systems}

A 2009 initiative, led by the North American Electric Reliability Corporation (NERC) developed technological assessments of both long and short term impacts of climate change on electricity generation. Two documents were produced as a result of the initiative which address several climate scenarios and suggested action for each to maintain grid reliability. This work was completed within the

NERC framework. Because of the uncertainties associated with climate predictions and the continual improvement of the metrics by which it is predicted and evaluated, and because all aspects of grid 
management are affected by extreme weather and climate change, periodic updates of this type should be part of NERC's ongoing development of reliability standards. In light of these considerations, NERC is likely to continue to have an interest in investing in such studies and in taking the actions necessary to reduce impacts of climate change on energy generation. NERC is funded by the energy distributors, so in order for research and policy concerning climate change to continue with this organization, energy distributors must see the need and the economic advantage to this policy development. Since their economy depends upon the maintenance of a functioning system, their interest likely is high, especially with regard to developing adaptive measures that strengthen the system in ways that provide long-term payoff in terms of productivity.

\section{Minimizing Environmental Stresses to the System: Building Resilience}

Energy infrastructure must be built strong enough to demonstrate multi-hazard resilience, both locally and for broader base. It must also be capable of operating reliably in regions of specific vulnerabilities such as $90 \mathrm{mph}$ winds, storm surges, flooding and heat waves. Development of the capability for predicting the effects of hazards on the performance of complex built structures along with costeffective design of new buildings and rehabilitation of old buildings are the most important aspects of building resilience into the energy infrastructure. The federal government funded National Institute of Standards and Technology (NIST) is the agency that would be responsible for this development. Since federal appropriations are voted on by congress, members of the House and Senate must approve of the use of these funds. In this case, especially since intense weather brought about by climate change is one of many of the multiple hazards facing built infrastructure, which include myriad other defenserelated hazards, funding for this effort is likely to continue as a national security measure. Thus, although many voting members of congress may have constituents who doubt the credibility of climate change, they do not discount the potential for threats to the system due to a variety of national enemies, and this alternative is politically quite feasible.

\section{Maximizing Clean and/or Sustainable Energy Generation and Use}

In order to make best use of alternative energy several actions should be taken 1) develop statewide inventories of energy alternatives, 2) make the records accessible to power companies, 3) build and maintain cooperative relationships among power companies and alternative energy supply companies (grid connections) and 4) employ battery backup rechargeable by a variety of types of energy sources. The first two of these actions fall under the responsibilities of the federally funded US Energy Information Administration (EIA). For this agency also, appropriations are made by Congress. Congress cut the EIA's 2011 budget by $14 \%$ and has not reinstated any of the previous funding for 2012 . Thus, information about smaller companies is simply not included in the inventories going forward, nor is the availability of the data collected made as available as it has been in the past. These budget cuts show a downgrading of importance afforded by congress to making energy information available. While continual updates to energy data is vital in helping to establish cooperation across energy supply companies, and should be reinstated in its full capacity, congress in its present state, may again choose to limit the budget for this effort. Although reduced funding does not make this alternative infeasible, it limits its reach. 


\section{Final Policy Recommendation}

Several Policy alternatives and descriptions of the benefits they offer toward protecting the electricity infrastructure from impacts of climate change have been presented for consideration. A cost/benefit analysis is presented below along with a recommended best final policy. This policy will necessarily involve first continued computational modeling of outcomes which will produce a portfolio of options to be considered in light of specific region-related risks. It is proposed that the modeling continue not only until reasonable policy at various levels of jurisdiction can be derived from its outcome but also on a continuing basis so that as improvements in the understanding of the state and trajectory of climate science along with advancements in technology arise, they can be incorporated into an appropriate and evolving policy. Thus, none of the recommendations below are immediately implementable. They are simply means to provide information for evolving policy as needs regarding adaptation to climate change emerge.

\section{Developing Policy for Responsible Maintenance of Energy Systems}

Total Score: 8.85

This is by far the most practical of the alternatives. Ongoing evaluation of maintenance and the adaptation of policy to the state of the grid is essential. As climate change begins to bring more frequent and intense impacts, the normal operations of the grid will receive new challenges. Upkeep of the grid maximizes resilience and minimizes potential harm to both human health and the environment. As the primary source for the development of energy policy, the North American Electric Reliability Council (NERC) sets Reliability Standards annually. In 2009, a new modeling effort led by the NERC Reliability Impacts of Climate Change Initiatives Task Force (RICCITF) was conducted to develop technological assessments of both long and short term impacts of climate change on electricity generation. This assessment was conducted within the NERC budget. Because of the uncertainties associated with climate predictions and the continual improvement of the metrics by which it is predicted and evaluated, periodic updates of this type should be part of NERC's ongoing development of reliability standards. It would be both easy and politically feasible to continue such studies, and added cost for these evaluations would be relatively minimal. Maintenance of the grid system in the form of smooth operations and communications; facilities design, connection and upkeep, resource demand and balancing; and emergency preparedness not only strengthens the system in light of climate change, but also in the event of any emergency, failure or potential failure.

\section{Minimizing Environmental Stresses to the System: Building Resilience}

Energy infrastructure must be built strong enough to demonstrate multi-hazard resilience, both locally and for broader base. It must also be capable of operating reliably in regions of specific vulnerabilities such as $90 \mathrm{mph}$ winds, storm surges, flooding and heat waves. Building resilience into power generation and distribution systems not only maximizes the continuation of local and regional economic productivity, it also minimizes health risk and environmental risk. The fewer power outages that occur and the shorter their duration when they do occur, the less is the opportunity for dependent systems to fail. If waste water facilities and storm drainage systems are kept running, sewage spills and deposition of toxic waste into natural waterways and freshwater sources can be avoided. Likewise, compromises of air quality such as spewed ash clouds from crippled power plants are less apt to occur.

In 2011 the National Institute of Standards and Technology (NIST) began to develop the capability for predicting the effects of hazards on the performance of complex built

Total Score: 8.7

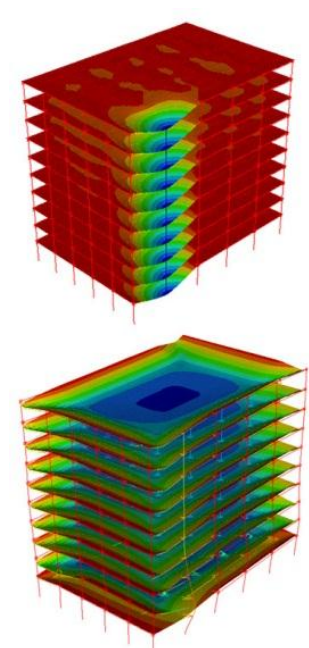


structures. The effects of these natural threats to be investigated are extreme wind, storm surge, fire, flooding, impacts, load bearing, and multi-hazard. Tests for structural response are included in the investigation as well as loss estimates for disaster consequences. The outcome of the project will be the development of cost-effective designs of new buildings for power generation and rehabilitation of old buildings for the purpose. Recent disasters and failures involving structures will inform the studies. The program will produce results that will inform new building codes and plans for bringing both old and new structures up to those standards. Since most members of congress are interested in the security of the national energy system, it is politically quite feasible to pass policy that will strengthen this infrastructure against multiple hazards, especially if terrorism is included as one of the hazards.

Unfortunately, however, since most of America's infrastructure is aging, much of its original resilience is already compromised due to cumulative ambient effects of several decades. Recommendations to emerge from this modeling effort will probably be suggestive of great expense needed to build stronger new structures and to retrofit old ones. It will be challenging as well to incorporate this hardening and security with energy efficiency. Nevertheless, this policy alternative receives highest marks overall for its ability to address the infrastructures adaptive needs to climate change.

\section{Managing Risk}

Total Score: 8.55

In order to manage the risks to energy infrastructure associated with climate change, there must be a process in place that allows for flexible and dynamically evolving adaptation of the system to continued updates and improvements in the scientific understanding of the impacts of climate change on various regions. The National Infrastructure Protection Plan (NIPP) has developed a Risk Management Framework for Energy Infrastructure. The framework establishes the processes for combining consequence, vulnerability, and threat information to produce a "comprehensive, systematic and evolving assessment of risks to assets, systems, networks, and functions of potential interest."

This options scores highly on minimization of human health risk and environmental risk since that is the primary objective of this modeling framework. While one of the likely recommendations to come from this modeling framework is that of maximizing resilience, the model itself does not do the maximizing. It does, however, measure the effectiveness of the programs implemented in the name of maximizing resilience. The outcome of the continued use of this framework is greater efficiency of policy. Policies that are ineffective can be exchanged for more robust ones. This framework is highly politically feasible since the main business of policy is that of risk aversion. It also must remain cost effective. This framework allows for the assessment of both ahead of and during the implementation of the policies it helps to develop. There is a cost associated with the model itself and its employment, however, so it does not score as highly as the NERC maintenance option.

\section{Maximizing Clean and Sustainable Energy Generation}

Total Score: $\mathbf{7 . 7 5}$

Although our past energy habits have already caused the climate equilibrium shift in which we currently find ourselves, maximization of clean and sustainable energy generation can begin a mitigation process for climate change in the long run. Multiple drivers for actions can reduce emissions and can produce multiple benefits. The most promising policy approaches are those that capitalize on natural synergies between climate protection and development priorities to advance both objectives simultaneously. Many of these synergies are in energy demand (e.g., efficiency and conservation, education and awareness) and some in energy supply (e.g., renewable options). 
Incorporating energy sources such as solar, wind and nuclear into a Smart Grid that can store and distribute that energy strategically according to need will lead to less emission of greenhouse gasses reducing the amount of global radiative forcing and resultant climate changes. The use of alternatives to conventional electricity, petroleum, and natural gas has the potential to enhance energy security by helping to distribute generation and diversify supply among various locations. Not only will the use of alternative energy sources help reduce a given power generation station's emission of greenhouse gases supporting the mitigation of climate change, these alternative sources can provide needed backup in the case of an energy emergency.

This option scores most highly on minimization of environmental risk in the long run since it addresses the problem at its root. With cleaner energy production, less $\mathrm{CO} 2$ is emitted into the atmosphere and the environment becomes less generally compromised. It misses a perfect score on this count, however, because since the atmospheric damage has already been done, the system is still vulnerable to the weather extremes that cause system failures and sewage spills. Additionally, the costs involved for converting to the Smart Grid, building new nuclear plants, for minimizing line losses in efficiency in distribution of wind-generated power from far-flung fields, for the development of optimal materials for solar collection, etc. are extremely high. This option is one that is needed, but it will take time and money and should be phased in at a manageable rate. These costs eat into profits for companies making the changes, which make this option less politically feasible as well.

Therefore, keeping up the maintenance of the system and making the system resilient against multiple hazards are the most immediately adoptable policies in this suite of alternatives, while investment in risk management must be ongoing. Finally, maximization of clean and sustainable energy should be a goal that is reached gradually as new technologies are developed and as individual companies, cities, regions and states update infrastructure and their programs.

\section{Criteria}

C1

C2

C3

C4

C5

Min Enviro

Weights

Alternatives Managing Risk

Maintenance

Build Resilience

Clean

Generation

\begin{tabular}{|c|c|c|c|c|c|}
\hline Max Resilience & Min Health Risk & Risk & Min Cost & Max Feas & Sum \\
\hline 0.3 & 0.2 & 0.2 & 0.15 & 0.15 & 1 \\
\hline 8 & 9 & 9 & 8 & 9 & 8.55 \\
\hline 9 & 9 & 9 & 9 & 8 & 8.85 \\
\hline 10 & 9 & 9 & 6 & 8 & 8.7 \\
\hline 8 & 8 & 9 & 6 & 7 & 7.75 \\
\hline
\end{tabular}




\section{References}

American Society of Civil Engineers, March 25, 2009, 2009 Report Card for America's Infrastructure.

http://www.asce.org/reportcard

http://autogeno.us/2007/11/19/kyoto-versus-the-montreal-protocol/

Blake, E.S., C.W. Landsea, E.J. Gibney (August, 2011). NOAA Technical Memorandum NWS NHC-6. "The Deadliest, Costliest, and Most Intense United States Tropical Cyclones from 1851 to 2010 (And Other Frequently Requested Hurricane Facts)".

Brohan, P., et al., 2006: Uncertainty estimates in regional and global observed temperature changes: A new dataset from 1850. J. Geophys. Res., 111, D12106, doi:10.1029/2005JD006548.

Chillymanjaro, September 9, 2011, San Diego power outage caused 2 million gallons of raw sewage spilled into Los Penasquitos Lagoon and Sweetwater River.

http://thewatchers.adorraeli.com/category/earth-changes/pollution-earth-changes

Climate Change 2007 - The Physical Science Basis. Contribution of Working Group I to the Fourth Assessment Report of the IPCC. Solomon, S., D. Qin, M. Manning, Z. Chen, M. Marquis, K.B. Averyt, M. Tignor and H.L. Miller (eds.) Cambridge University Press, Cambridge, United Kingdom and New York, NY, USA.

DEFRA Report. 2011. Climate Resilient Infrastructure: Preparing for a Changing Climate, Synthesis of the independent studies commissioned by the Government's Infrastructure \& Adaptation Project.

Department of Homeland Security, Department of Energy (2010). Energy Sector-Specific Plan: An Annex to the National Infrastructure Protection Plan. http://www.dhs.gov/xlibrary/assets/nipp-ssp-energy-2010.pdf

Department of Homeland Security, NIPP

http://www.dhs.gov/xabout/structure/gc 1257533087944.shtm

EIA

http://www.eia.gov/cneaf/electricity/page/data.html

EIA Budget

http://www.eia.gov/about/budget performance.cfm

Emanuel, K., 2003: Tropical cyclones. Annu. Rev. Earth. Planet. Sci., 31, 75-104.

Federal Energy Regulatory Commission (FERC) http://www.ferc.gov/industries/electric/indus-act/reliability.asp

Ganguly, A.R., K. Steinhauser, D.J. Erickson, III, M. Branstetter, E.S. Parish, N. Singh, J.B. Drake, L. Buja (2009). Higher trends but larger uncertainty and geographic variability in 21st century temperature and heat waves, Proceedings of the National Academy of Sciences, 106, 37, 15555 - 15559, doi:10.1073/pnas.0904495106.

Gustafson, Craig, Sept. 8, 2011, Updated 6:01 a.m. , Sept. 9, 2011, Unprecedented outage left millions in the dark. http://signonsandiego.printthis.clickability.com/pt/cpt?expire=\&title=Unprecedented+outage+left+millions+in+th e+dark+-

+SignOnSanDiego.com\&urlID=460051427\&action=cpt\&partnerID=86541\&fb=Y\&url=http\%3A\%2F\%2Fwww.signons andiego.com\%2Fnews\%2F2011\%2Fsep\%2F08\%2Fwidespread-power-outages-across-san-diego-county\%2F 
Hansen, J., et al., 2001: A closer look at United States and global surface temperature change. J. Geophys. Res., 106, 23947-23963.

Johnson, Jeremy and Alex Lefebvre, August 20, 2003, US: Impact of Northeast Blackout Continues to Emerge, World Socialist Web Site. http://www.wsws.org/articles/2003/aug2003/blck-a20.shtml

Keegan, Kyle, Four Big Unanswered Blackout Questions, Posted: Friday, September 9, 2011 8:20 pm; Updated: 5:10 pm, Fri Oct 14, 2011. http://www.voiceofsandiego.org/data-drive/article dc4aabe6-db5b-11e0-97ba$\underline{001 c c 4 c 03286 . h t m l}$

Kirshen, P., M. Ruth, and W. Anderson, 2008. Interdependencies of Urban Climate Change Impacts and Adaptation Strategies: A Case Study of Metropolitan Boston USA, Climatic Change 86: 105-122.

Lee, Morgan, Sept. 22, 2011, Grid operators didn't share info during blackout, SignOn San Diego. http://www.signonsandiego.com/news/2011/sep/22/5-authorities-handle-electric-grid-didnt-share-inf

Lee, Mike, September 27, 2011, Blackout's sewage spills 75 percent greater than reported. http://www.signonsandiego.com/news/2011/sep/27/blackouts-sewage-spills-far-greater-reported

Levinson, D.H., and A.M. Waple (eds.), 2004: State of the climate in 2003. Bull. Am. Meteorol. Soc., 85(6), S1-S72.

Lugina, K.M., et al., 2005: Monthly surface air temperature time series area-averaged over the 30-degree latitudinal belts of the globe, 1881-2004. In: Trends: A Compendium of Data on Global Change. Carbon Dioxide Information Analysis Center, Oak Ridge National Laboratory, US Department of Energy, Oak Ridge, TN, http://cdiac.esd.ornl.gov/trends/temp/lugina/lugina.html.

McDonald, Jeff and Morgan Lee, September 16, 2011, Outage Had Roots in Mexico, too, SignOn San Diego. http://signonsandiego.printthis.clickability.com/pt/cpt?expire=\&title=Outage+had+roots+in+Mexico $\% 2 \mathrm{C}+$ too+\%7C +SignOnSanDiego.com\&urlID=460595072\&action=cpt\&partnerID=86541\&fb=Y\&url=http\%3A\%2F\%2Fwww.signons andiego.com\%2Fnews\%2F2011\%2Fsep\%2F16\%2Foutage-had-roots-in-mexico-too\%2F

Meehl, G. A. \& Tebaldi, C. More intense, more frequent, and longer lasting heat waves in the 21st century. Science 305, 994-997 (2004).

Minkel, J.R. (2008). The 2003 Northeast Blackout-Five Years Later, Scientific American, http://www.scientificamerican.com/article.cfm?id=2003-blackout-five-years-later

Natural Resources and Culture Committee Executive Summary Sheet, September 22, 2011. "Impacts of the September 8, 2011 Countywide Blackout of the Public Utilities Department." City of San Diego.

National Association of State Energy Officials, National Association of Regulatory Utility Commissioners (2009). State Energy Assurance Guidelines, 3.1.

National Energy Reliability Council 2010:

http://www.balch.com/files/upload/FERC Order Conditionally Accepting 2010 BusinessPlan Budget. pdf

NERC 2009 Long Term Reliability Assessment

http://www.nerc.com/files/2009 LTRA.pdf 
National Institute of Standards and Technology

http://www.nist.gov/el/building materials/program structures.cfm

NIST Brief Budget

http://www.nist.gov/public affairs/factsheet/disaster-resilience2013.cfm

Organization for Economic Co-operation and Development (OECD) work on Adaptation to Climate Change (2010). http://www.oecd.org

O'Rourke, T.D. (2007). Critical Infrastructure, Interdependencies, and Resilience, The Bridge, 37/1, 22-29. http://www.nae.edu/cms/Publications/TheBridge/Archives/7404.aspx

The Ozone Hole-The Montreal Protocol on Substances that Deplete the Ozone Layer. http://www.theozonehole.com/montreal.htm

Parry, M.L., O.F. Canziani, J.P. Palutikof, P.J. van der Linden and C.E. Hanson (eds) 2007, Contribution of Working Group II to the Fourth Assessment Report of the Intergovernmental Panel on Climate Change. Cambridge University Press, Cambridge, United Kingdom and New York, NY, USA. 976 pp.

Reliability Impacts of Climate Change Initiatives

http://www.nerc.com/files/RICCI 2010.pdf

REMUS

http://www.titanenergy.com/PDF/TEDI October\%202008 web.pdf

SAP 4.5 (CCSP), 2007. Effects of Climate Change on Energy Production and Use in the United States, a Report by the U.S. Climate Change Science Program and the subcommittee on Global Change Research [Thomas J. Wilbanks, et al., eds)], Department of Energy, Office of Biological \& Environmental Research, Washington, DC., 160 pp.

Sinigalliano, C.D. et al. (2007) Impacts of Hurricanes Katrina and Rita on the microbial landscape of the New Orleans area, PNAS, May 22, 2007 vol. 104 no. 21 9029-9034 , doi: 10.1073/PNAS.0610552104.

http://www.pnas.org/content/104/21/9029.full

Smith, T.M., and R.W. Reynolds, 2005: A global merged land and sea surface temperature reconstruction based on historical observations (1880-1997). J. Clim., 18, 2021-2036.

SREX, IPCC. 2012. Summary for Policymakers, pp. 1-19 in C.B. Field, V. Barros, et al., (eds), Managing the Risks of Extreme Events and Disasters to Advance Climate Change Adaptation, A Special Report of Working Groups I and II of the Intergovernmental Panel on Climate Change, Cambridge University Press, Cambridge and New York.

State Energy Assurance Guidelines, 2009

http://www.naseo.org/eaguidelines/

Sunstein, Cass R., Montreal vs. Kyoto: A Tale of Two Protocols. Harvard Environmental Law Review, Forthcoming; AEI-Brookings Joint Center Working Paper No. 06-17; U of Chicago, Public Law Working Paper No. 136; U Chicago Law \& Economics, Olin Working Paper No. 302. Available at SSRN: http://ssrn.com/abstract=913395

U.S.-Canada Power System Outage Task Force, April 2004, Final Report on the August 14, 2003 Blackout in the United States and Canada: Causes and Recommendations. https://reports.energy.gov/ 
U.S. Environmental Protection Agency, 2010. Green Infrastructure Case Studies, U.S. EPA, Washington, DC, August.

Villasenor, J., 2011. Securing an Infrastructure Too Complex to Understand, Brookings Institution, Sep 23.

Whole Building Design Guide

http://www.wbdg.org/resources/resistexplosivethreat.php

Wilbanks, T., et al. (2012). Climate Change and Infrastructure, Urban Systems, and Vulnerabilities: Technical Report to the US Department of energy in Support of the National Climate Assessment. In Progress.

http://www.wiresgroup.com/images/NERC 2009 LTRA.pdf

Wu, S. Y., Najjar, R., \& Siewert, J. (2009). Potential impacts of sea-level rise on the Midand Upper-Atlantic Region of the United States. Climatic Change, 95, 121-138.

Zhang, K.Q., Douglas, B.C., \& Leatherman, S.P. (2000). Twentieth-century storm activity along the U.S. east coast. Journal of Climate, 13, 1748-1761.

Zimmerman, R. , 2006. Critical Infrastructure and Interdependency, Chapter 35, pp. 523-545 in D.G. Kamien (ed), The McGraw-Hill Homeland Security Handbook, McGraw-Hill, New York. 